\title{
Article \\ Restriction of RAP\% in HMA Based on Aggregate Gradation and Binder Properties
}

\author{
Bharath Gottumukkala ${ }^{1, *}$, Sudhakar Reddy Kusam ${ }^{2}$, Vivek Tandon ${ }^{3}{ }^{\mathbb{D}}$, Amaranatha Reddy Muppireddy ${ }^{2}$ \\ and Ramya Sri Mullapudi 4 \\ 1 Flexible Pavement Division, Central Road Research Institute, New Delhi 110025, India \\ 2 Civil Engineering Department, Indian Institute of Technology, Kharagpur 721302, India; \\ ksreddy@civil.iitkgp.ac.in (S.R.K.); manreddy@civil.iitkgp.ac.in (A.R.M.) \\ 3 Civil Engineering Department, University of Texas, El-Paso, TX 79968, USA; vivek@utep.edu \\ 4 Civil Engineering Department, Indian Institute of Technology Hyderabad, Kandi, Sangareddy 502284, India; \\ ramyamullapudi@ce.iith.ac.in \\ * Correspondence: bharat.varma.020@gmail.com
}

check for updates

Citation: Gottumukkala, B.; Kusam, S.R.; Tandon, V.; Muppireddy, A.R.; Mullapudi, R.S. Restriction of RAP\% in HMA Based on Aggregate Gradation and Binder Properties. CivilEng 2021, 2, 811-822. https://doi.org/10.3390/ civileng2030044

Academic Editors: Luis Picado-Santos and José Neves

Received: 4 August 2021

Accepted: 9 September 2021

Published: 17 September 2021

Publisher's Note: MDPI stays neutral with regard to jurisdictional claims in published maps and institutional affiliations.

Copyright: (c) 2021 by the authors. Licensee MDPI, Basel, Switzerland. This article is an open access article distributed under the terms and conditions of the Creative Commons Attribution (CC BY) license (https:// creativecommons.org/licenses/by/ $4.0 /)$.

\begin{abstract}
The use of recycled asphalt pavement (RAP) in pavement construction reduces the project cost and helps in conserving the naturally occurring aggregates. To incorporate RAP in hot mix asphalt, it is vital to know the amount and quality of the reclaimed binder. Three new asphalt binders were selected for this investigation. RAP material from one source was blended in different proportions with VG-10 and VG-30. Penetration, softening point, G*/sin $\delta, G * \sin \delta$ and binder fatigue life Nf (from Linear Amplitude Sweep test) values of different blends were compared. The milled RAP aggregate gradation varied from source to source due to factors such as the gradation of the mix used in the existing layer, milling method and processing of RAP material. This variability controls the use of higher proportions of RAP in new mixes. To investigate the effect of RAP gradation on the proportion of RAP that can be used in the new mix, RAP sources with different gradation (three dense and two gap gradations) were selected. The proportion of RAP that can be used for preparing mixes with these gradations varied significantly with the source of RAP, and the target gradation. In most cases, it was found that allowable RAP percentages are smaller for the gap gradations compared to those permitted for dense gradations. The proportion of RAP in a mix can be increased by selecting an appropriate gradation for a RAP source or by using a suitable RAP source for a given gradation.
\end{abstract}

Keywords: reclaimed asphalt pavement; target gradation; aggregate gradation

\section{Introduction}

Considering that major pavement construction projects in India involve new carriageways, rehabilitation and reconstruction of existing pavements, recycling of the asphalt material needs to be seriously considered. Thus, the feasibility of utilizing large proportions is an important consideration.

Though a very recent practice in India, the utilization of RAP in bituminous layers has been practiced for several years in different countries, such as the USA's majority of State transportation departments allowing RAP in HMA mixtures, with the 2007 average national usage rate estimated to be 12 percent [1]. In addition, most of the state road agencies in the USA and Canada permit RAP in surface and base layers, while some states allow little or no RAP in bituminous mixes due to performance concerns [1].

The number of US and Canadian state agencies allowing RAP usage in surface course layers up to $10,19,29$, and above $30 \%$ are $43,35,20$, and 5, respectively [1]. Similarly, the number of state agencies allowing RAP usage in base course layers (bi-tuminous mixes) up to $10,19,29$, and above $30 \%$ are $45,43,36$, and 15 , respectively [1]. 
RAP in dense-graded mixes is commonly used in Europe, and is allowed up to $10 \%$ in stone mastic asphalt (SMA) mixes in the UK. In New Zealand and Australia [2], most agencies allow $15 \%$ or more in dense graded bituminous mixes and smaller quantities in surface layers. Recently in Australia, it incorporated 5\% RAP material into Airport Asphalt Resurfacing [3]. Hot recycled mix design includes determining the blending proportions of RAP material and new aggregate fractions to meet target gradation and selecting virgin binder type and quantity. First, blending charts, based on the viscosity or Superpave rutting parameter $G^{*} / \sin \delta$, are used to select virgin binder grade [4,5]. Then, different trial mixes are prepared using virgin binder contents and the optimum bitumen contents are selected according to appropriate performance criteria.

The Ministry of Road Transport and Highways, Government of India [6] recommends that the penetration value of the recovered binder from the reclaimed bituminous material, before mixing, should exceed 15 pen $(\mathrm{d}$ in $\mathrm{mm}$ ) for using more than $10 \% \mathrm{RAP}$ in the mix. MoRTH [6] also suggests that the reclaimed bituminous material be pre-treated, processed and a homogenous mix produced with the maximum particle size of reclaimed material not exceeding $40 \mathrm{~mm}$. According to European specifications [7], the virgin binder need not be changed for RAP contents to be used in surface and base courses that are less than $10 \%$ and $20 \%$, respectively. The penetration and softening point values are estimated using appropriate blending charts or equations for higher RAP contents. European specifications for reclaimed asphalt [8] and the guidelines adopted by different European countries [2] recommend that the penetration value of the extracted RAP binder should be a minimum of $15 \mathrm{dmm}$, and that the softening point should be less than $70^{\circ} \mathrm{C}$. Limiting values for penetration and softening point of RAP binder for using the RAP material in bituminous mixes, adopted by different European Countries, are given in Table 1 [9]. NCHRP 452 report [9] provides guidelines for designing RAP mixes per the Superpave mix design procedure.

Table 1. Limiting Values of RAP Binder Properties for Recycling.

\begin{tabular}{|c|c|c|c|c|c|c|c|c|}
\hline \multirow{2}{*}{ Property } & \multicolumn{8}{|c|}{ Limiting Value In } \\
\hline & Belgium & France & Germany & Ireland & Poland & Portugal & Slovenia & UK \\
\hline $\begin{array}{l}\text { Penetration } \\
(1 / 10 \mathrm{~mm})\end{array}$ & $>10$ & $>5$ & $>15$ & $>15$ & 15 & $>15$ & - & $>15$ \\
\hline Softening point $\left({ }^{\circ} \mathrm{C}\right)$ & - & $<77$ & $<70$ & - & $<70$ & $<70$ & $<70$ & - \\
\hline
\end{tabular}

This study proposes to evaluate the feasibility of utilizing a higher proportion of RAP in the hot bituminous mix based on the recycled binder's physical and rheological properties. It is also proposed to evaluate the effect of different types of virgin binder and aggregate gradation on the maximum proportion of RAP incorporated in the recycled mix to satisfy the binder properties and target gradations. Thus, the main objectives of this study are to evaluate the combined properties of VG10 and VG30 (VG indicates Viscosity Grading that specifies grade of binder based on absolute viscosity at $60^{\circ} \mathrm{C}$ [10]) blended with RAP binder and to identify the maximum proportion of RAP content that can be added in a mix.

\section{Selection of Virgin Materials for Investigation}

Indian Roads Congress guideline IRC 111 [11] recommends a VG30 binder for dense bituminous mixes for climatic conditions defined by "minimum daily average air temperature more than $-10^{\circ} \mathrm{C}$ and maximum daily average air temperature above $30{ }^{\circ} \mathrm{C}^{\prime \prime}$ and VG40 binder or modified bitumen of equivalent stiffness for surface layers for projects with more than 2000 commercial vehicles per day per lane and with the maximum daily average temperature of more than $40{ }^{\circ} \mathrm{C}$.

Hence, VG10, VG30 and VG40 binders were selected for this study. The VG10 and VG30 virgin binders and the binder extracted from one RAP mix (Source from the project near Kharagpur, India) were blended in different proportions for evaluation. VG40 binder 
is recommended for roads carrying heavy loads and design traffic of more than $30 \mathrm{msa}$ (million standard axle of $80 \mathrm{kN}$ ), IRC 37 [12]. For the present study, three dense and two gap graded target aggregate gradations were considered. Table 2 gives the gradations selected for this work. Out of the five gradations shown in Table 2, three aggregate gradations selected correspond to the dense gradations recommended for bituminous concrete (BC-1: BC) and dense bituminous macadam (DBM-2: DBM) by the Ministry of Road Transport and Highway [6] and Texas-b dense gradation of Texas Department of Transportation [13] and two gap gradations: Stone matrix asphalt (SMA) of MoRTH [6] and coarse matrix high binder CMHB-C: Texas Gap [13].

Table 2. Aggregate gradations in the present study.

\begin{tabular}{|c|c|c|c|c|c|c|c|c|c|c|}
\hline \multirow{3}{*}{$\begin{array}{l}\text { Sieve } \\
\text { Size } \\
(\mathrm{mm})\end{array}$} & \multicolumn{10}{|c|}{ Cumulative \% Passing by Weight of Total Aggregate } \\
\hline & \multicolumn{2}{|c|}{ BC } & \multicolumn{2}{|c|}{ DBM } & \multicolumn{2}{|c|}{ SMA } & \multicolumn{2}{|c|}{ Texas Gap } & \multicolumn{2}{|c|}{ Texas-b } \\
\hline & Upper & Lower & Upper & Lower & Upper & Lower & Upper & Lower & Upper & Lower \\
\hline 37.5 & 100 & 100 & 100 & 100 & 100 & 100 & 100 & 100 & 100 & 100 \\
\hline 26.5 & 100 & 100 & 100 & 90 & 100 & 100 & 100 & 100 & 100 & 98 \\
\hline 19 & 100 & 90 & 95 & 71 & 100 & 90 & 100 & 98 & 98 & 84 \\
\hline 13.2 & 79 & 59 & 80 & 56 & 70 & 45 & 85 & 72 & & \\
\hline 9.5 & 72 & 52 & & & 60 & 25 & 70 & 50 & 80 & 60 \\
\hline 4.75 & 55 & 35 & 54 & 38 & 28 & 20 & 45 & 30 & 60 & 40 \\
\hline 2.36 & 44 & 28 & 42 & 28 & 24 & 16 & 27 & 17 & 43 & 29 \\
\hline 1.18 & 34 & 20 & & & 21 & 13 & 27 & 5 & & \\
\hline 0.6 & 27 & 15 & & & 18 & 12 & 27 & 5 & 28 & 13 \\
\hline 0.3 & 20 & 10 & 21 & 7 & 20 & 10 & 27 & 5 & 20 & 6 \\
\hline 0.15 & 13 & 5 & & & & & & & & \\
\hline 0.075 & 8 & 2 & 8 & 2 & 12 & 8 & 9 & 5 & 7 & 2 \\
\hline
\end{tabular}

\section{RAP Material}

RAP material was collected from six different sources (five from the Indian cities Kharagpur, Allahabad, Kolkata, Ongole and Varanasi, and one from the USA, El Paso, Texas). Binder from the RAP material was extracted using a centrifuge extractor. The distillation method was used to recover the binder from the solvent.

For the El Paso RAP material, Rotavapor was used for recovering the binder from the solvent. The optimum binder contents in the RAP material collected from Kharagpur, Allahabad, Kolkata, Ongole, Varanasi and El Paso are 4.5\%, 4.96\%, 4.32\%, 4.6\%, 4.69\% and $4.19 \%$, respectively [14]. Figure 1 shows the gradations of the RAP aggregates obtained from RAP material collected from different sources. 


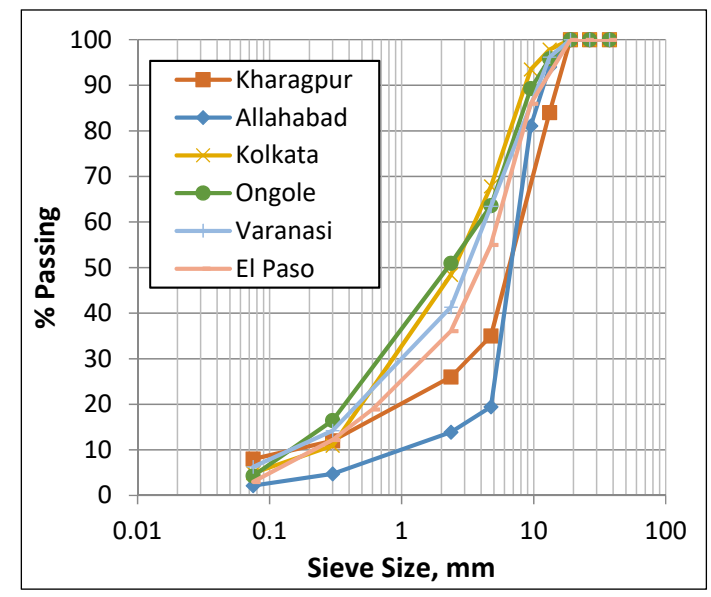

Figure 1. Gradations of RAP aggregates used in the present study.

\section{Preliminary Evaluation of Binders}

Different physical and consistency properties of the three virgin binders were determined as per relevant Indian standards. The test results of the three unmodified VG10, VG30 and VG40 binders are given in Table 3. Properties of the recovered from the RAP materials are given in Table 4 . Recovered RAP binders Viscosity at $60^{\circ} \mathrm{C}$ were obtained using Dynamic Shear Rheometer (due to the non-availability of specified tube).

Table 3. Results of Tests Conducted on Unmodified Binders.

\begin{tabular}{|c|c|c|c|c|c|c|}
\hline \multirow{2}{*}{ Property Evaluated } & \multicolumn{2}{|c|}{ VG10 } & \multicolumn{2}{|c|}{ VG30 } & \multicolumn{2}{|c|}{ VG40 } \\
\hline & Result & Spec* & Result & Spec* & Result & Spec* \\
\hline $\begin{array}{c}\text { Penetration at } 25^{\circ} \mathrm{C}, 100 \mathrm{~g}, 5 \mathrm{~s}, 0.1 \mathrm{~mm} \\
\text { ASTM D36 [15] }\end{array}$ & 90 & Min 80 & 68 & Min 45 & 39 & Min 35 \\
\hline $\begin{array}{c}\text { Softening Point, }{ }^{\circ} \mathrm{C} \\
\text { ASTM D5 [16] }\end{array}$ & 41 & Min 40 & 48 & Min 47 & 54 & Min 50 \\
\hline $\begin{array}{l}\text { Viscosity at } 60^{\circ} \mathrm{C} \text {, Poise } \\
\text { ASTM D3381 [10] }\end{array}$ & 1879 & - & 4689 & - & 6471 & - \\
\hline
\end{tabular}

* As per IS: 73 [17].

Table 4. Results of Tests Conducted on Recovered RAP Binders.

\begin{tabular}{|c|c|c|c|c|c|c|}
\hline Parameter & Kharagpur & Ongole & Varanasi & Kolkata & Allahabad & El Paso \\
\hline $\begin{array}{l}\text { Penetration at } 25^{\circ} \mathrm{C}, 100 \mathrm{~g}, 5 \mathrm{~s}, 0.1 \mathrm{~mm} \\
\text { ASTM D5 [16] }\end{array}$ & 18 & 14 & 14 & 17 & 19 & - \\
\hline $\begin{array}{l}\text { Softening Point (R\&B), }{ }^{\circ} \mathrm{C}, \\
\text { ASTM D36 [15] }\end{array}$ & 68 & 74 & 75 & 71 & 68 & - \\
\hline $\begin{array}{c}\text { Dynamic Viscosity **, P } \\
\text { IS: } 73 \text { [17] }\end{array}$ & 13,913 & 34,075 & 36,786 & 17,297 & 12,514 & 16,629 \\
\hline
\end{tabular}

\footnotetext{
** Viscosity was determined by Dynamic Shear Rheometer.
}

Physical properties and rheological characteristics of the following binders were evaluated using Dynamic Shear Rheometer (DSR):

- VG10, VG30 and VG40 virgin binders

- RAP binders extracted from six different RAP sources

- Blends of binders extracted from different RAP mixes prepared using Kharagpur RAP in different proportions (10 to 50\%) and VG10 and VG30 virgin binders

The average bitumen content in the Kharagpur RAP was $4.5 \%$ (by weight of mix). Different combinations of mixes with varying RAP contents $0 \%, 10 \%, 20 \%, 30 \%, 40 \%, 50 \%$ 
and $100 \%$ were prepared with fixed quantity of virgin binder ( $4.5 \%$ by weight of total mix) to generate different RAP binder-to-total binder $(\mathrm{R} / \mathrm{T})$ ratios of $0,0.09,0.16,0.23,0.28,0.33$ and 1.0. The mixes were prepared with two different binders, VG10 and VG30. The total weight of the mix considered was $2000 \mathrm{~g}$. RAP Material heated for no more than two hours at $110^{\circ} \mathrm{C}$. To compensate for the introduction of a lower temperature material, the virgin aggregate was heated above the mixing temperature by a specified amount. Although actual mix temperatures vary, a good rule of thumb is to increase the temperature of the virgin aggregates by $0.5^{\circ} \mathrm{C}$ for every percent of RAP used in the mix (MS-2, 7th edition [5]. An equiviscous method was followed for finding the binder mixing temperature. Virgin binders VG10 and VG30 were heated at $145^{\circ} \mathrm{C}$ and $160{ }^{\circ} \mathrm{C}$, respectively, and then the virgin binder was added and mixed thoroughly for $1 \mathrm{~min}$. The binder was extracted from the mix after it was cooled to ambient temperature using the solvent method.

Different binder properties such as penetration, softening point, Superpave rutting $(G * / \sin \delta)$ and fatigue $(G * \sin \delta)$ parameters were evaluated for the binder samples extracted from different combinations of mixes. $G^{*} / \sin \delta$ test was conducted at different temperatures and frequencies using Dynamic Shear Rheometer. Additionally, Multiple stress creep recovery (MSCR) test at $60{ }^{\circ} \mathrm{C}$ and a Linear amplitude sweep (LAS) test at $25^{\circ} \mathrm{C}$ were also conducted on the binders to evaluate the rutting and fatigue susceptibilities. Linear amplitude sweep test was conducted on the extracted binders after PAV aging them. Results of the tests conducted on different binders are given in Table 5. As expected, the penetration value decreased and softening point value increased with increasing RAP content in the blend.

Table 5. Physical Properties of Binders.

\begin{tabular}{cccc}
\hline Binder & $\begin{array}{c}\text { Recycled } \\
\text { Binder/Total Binder }\end{array}$ & $\begin{array}{c}\text { Penetration } \\
(\mathbf{d} \text { in } \mathbf{~ m m})\end{array}$ & $\begin{array}{c}\text { Softening Point } \\
\left({ }^{\circ} \mathbf{C}\right)\end{array}$ \\
\hline VG10 & 0 & 90 & 41 \\
\hline VG10-10\% RAP & 0.09 & 81 & 43 \\
\hline VG10-20\% RAP & 0.16 & 68 & 44 \\
\hline VG10-30\% RAP & 0.23 & 64 & 48 \\
\hline VG10-40\% RAP & 0.28 & 61 & 56 \\
\hline VG10-50\% RAP & 0.33 & 39 & 61 \\
\hline VG30 & 0 & 68 & 48 \\
\hline VG30-10\% RAP & 0.09 & 64 & 54 \\
\hline VG30-20\% RAP & 0.16 & 54 & 57 \\
\hline VG30-30\% RAP & 0.23 & 47 & 59 \\
\hline VG30-40\% RAP & 0.28 & 39 & 64 \\
\hline VG30-50\% RAP & 0.33 & 29 & \\
\hline
\end{tabular}

\section{Rheological Properties of Binder}

\subsection{Binder Rutting Parameter $G * / \sin \delta$}

A higher complex modulus $\left(G^{*}\right)$ value and lower phase angle $(\delta)$ value are desirable for better rutting resistance. Higher $G^{*}$ values represent stiffer binders that are more resistant to rutting and lower $\delta$ values suggest greater elasticity of the binders with smaller plastic deformation. Thus, higher $G^{*} / \sin \delta$ signifies more resistance to rutting by the binder [18]. Superpave binder specifications for satisfactory rutting performance of binders $\left(\mathrm{G}^{*} / \sin \delta \geq 1.0 \mathrm{kPa}\right)$ were followed as per SP-1 [18]. The DSR test was carried out as per ASTM D7175-08 [19] on the new and recovered binders selected in this study. Unaged and RTFO aged binders were tested over a high service temperature range of $46{ }^{\circ} \mathrm{C}$ to $82{ }^{\circ} \mathrm{C}$ and at different frequencies. PAV-aged binders were tested at an intermediate temperature 
of $25^{\circ} \mathrm{C}$ and $10 \mathrm{rad} / \mathrm{s}$ frequency. The measured $\mathrm{G} * / \sin \delta$ values of different binders are given in Tables 6 and 7 .

Table 6. $G^{*} / \sin \delta$ for RAP Binders.

\begin{tabular}{cccccccc}
\hline \multirow{2}{*}{$\begin{array}{c}\text { Temperature } \\
\left({ }^{\circ} \mathbf{C}\right)\end{array}$} & Kharagpur & Allahabad & Kolkata & Ongole & Varanasi & El Paso \\
\cline { 2 - 8 } & 8.4 & 7.58 & 8.12 & 18.8 & 19.4 & 14.78 & 7.92 \\
\hline 70 & 3.84 & 3.37 & 3.75 & 7.65 & 7.85 & 3.43 & 4.26 \\
\hline 76 & 1.8 & 1.64 & 1.98 & 3.4 & 1.61 & 2.36 \\
\hline 82 & 0.92 & 0.86 & 0.9 & 1.56 & 0.7 & 1.3 \\
\hline 88 & 0.56 & 0.49 & 0.29 & 0.79 & & & \\
\hline
\end{tabular}

Table 7. $G * / \sin \delta$ for Virgin Binders.

\begin{tabular}{ccccccc}
\hline \multirow{2}{*}{$\begin{array}{c}\text { Temperature } \\
\left({ }^{\circ} \mathbf{C}\right)\end{array}$} & \multicolumn{2}{c}{ VG10 } & \multicolumn{2}{c}{ VG30 } & \multicolumn{2}{c}{ VG40 } \\
\cline { 2 - 7 } & Un-Aged & RTFO-Aged & Un-Aged & RTFO-Aged & Un-Aged & RTFO-Aged \\
\hline 46 & 15.49 & 27.40 & 28.6 & 61.8 & 41.2 & 76.66 \\
\hline 52 & 5.71 & 11.61 & 16.19 & 33.29 & 18.01 & 36.07 \\
\hline 58 & 2.22 & 4.55 & 6.79 & 13.06 & 8.78 & 18.01 \\
\hline 64 & 1.06 & 1.74 & 2.91 & 5.27 & 3.733 & 10.18 \\
\hline 70 & 0.53 & 0.85 & 1.33 & 2.29 & 2.43 & 7.69 \\
\hline 76 & 0.27 & 0.42 & 0.65 & 1.09 & 1.33 & 3.82 \\
\hline 82 & 0.16 & 0.22 & 0.34 & 0.55 & 0.76 & 1.15 \\
\hline
\end{tabular}

The $G^{*} / \sin \delta$ values of binders decreased with increased temperature and increased with aging. VG10 binder has the lowest $G^{*} / \sin \delta$ value at all temperatures and for all aging conditions. Figure 2 shows the $G^{*} / \sin \delta$ with a variation of RAP binder proportion in the total binder. The binder rutting parameter $G^{*} / \sin \delta$ values indicate that the addition of reclaimed binder improved the rut resistance of the binder.

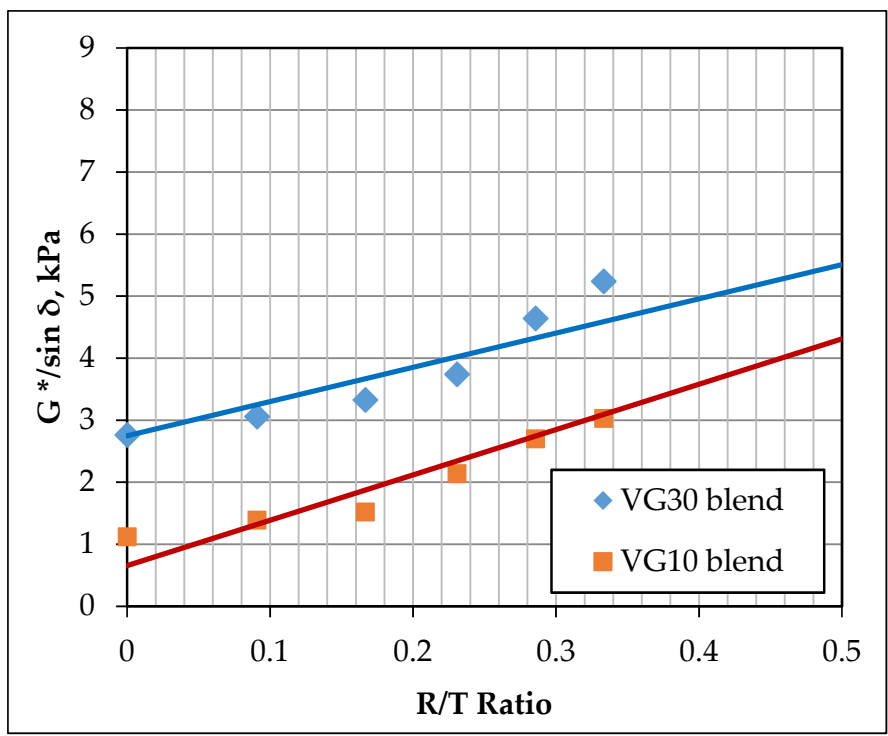

Figure 2. Variation of $G^{*} / \sin \delta$ with $R / T$ Ratio. 


\subsection{Multiple Stress Creep and Recovery Test}

The non-recoverable creep compliance $\left(\mathrm{J}_{\mathrm{nr}}\right)$ parameter is a good indicator of the rut resistance of binders. A higher $\mathrm{J}_{\mathrm{nr}}$ value suggests lower resistance to rutting. The nonrecoverable creep compliance obtained at $3200 \mathrm{~Pa}$ was reported to have a better correlation with mix rutting than $G^{*} / \sin \delta$ [20]. The value of $J_{n r}$ is calculated using Equation (1)

$$
\mathrm{J}_{\mathrm{nr}}=\gamma_{\mathrm{u}} / \tau
$$

where, $\gamma_{\mathrm{u}}=$ Average non-recovered strain; $\tau=$ stress applied during creep.

The MSCR test was performed on the extracted binders at two stress levels, $100 \mathrm{~Pa}$ and $3200 \mathrm{~Pa}$, as per ASTM D7405-10 [20]. Stress sensitivity of the binders was evaluated in terms of $\mathrm{J}_{\mathrm{nr} \text {-diff }}$ as per Equation (2) by comparing the $\mathrm{J}_{\mathrm{nr}}$ values obtained for $100 \mathrm{~Pa}$ and 3200 Pa stress levels.

$$
\mathrm{J}_{\mathrm{nr}-\text { diff }}=\left(\mathrm{J}_{\mathrm{nr} 3200}-\mathrm{J}_{\mathrm{nr} 100}\right) / \mathrm{J}_{\mathrm{nr} 100}
$$

Table 8 gives the non-recoverable creep compliance values obtained from the MSCR test for $100 \mathrm{~Pa}$ and $3200 \mathrm{~Pa}$ stress levels for different binders. The test was performed at $60^{\circ} \mathrm{C}$, which can be considered the average high service pavement temperature in India. The $\mathrm{J}_{\mathrm{nr}}$ values of RAP binders are found to be smaller than those of the new binder.

\begin{tabular}{|c|c|c|c|c|}
\hline \multirow{2}{*}{ Binder } & \multirow{2}{*}{ R/T Ratio } & \multicolumn{2}{|c|}{$\begin{array}{l}\mathrm{Jnn}_{\mathrm{nr}}(1 / \mathrm{kPa}) \text { for a } \\
\text { Stress Level of }\end{array}$} & \multirow{2}{*}{$\mathrm{J}_{\mathrm{nr}-\text { diff }}=\left(\mathrm{J}_{\mathrm{nr} 3200}-\mathrm{J}_{\mathrm{nr} 100}\right) / \mathrm{J}_{\mathrm{nr} 100}$} \\
\hline & & $100 \mathrm{~Pa}$ & $3200 \mathrm{~Pa}$ & \\
\hline VG30 & 0 & 0.297 & 0.3278 & 0.1037 \\
\hline VG30-10\% RAP & 0.09 & 0.2476 & 0.2702 & 0.0913 \\
\hline VG30-20\% RAP & 0.16 & 0.2211 & 0.2396 & 0.0837 \\
\hline VG30-30\% RAP & 0.23 & 0.182 & 0.204 & 0.1209 \\
\hline VG30-40\% RAP & 0.28 & 0.16348 & 0.1755 & 0.0735 \\
\hline VG30-50\% RAP & 0.33 & 0.1313 & 0.1408 & 0.0724 \\
\hline
\end{tabular}

Table 8. MSCR Test Results.

\subsection{Binder Fatigue Parameter $G * \sin \delta$}

Fatigue cracking is one of the major pavement distresses due to repeated load applications applied mainly at intermediate service temperature [21]. A binder with a very high $\mathrm{G}^{*}$ and high $\sin \delta$ is expected to be less fatigue resistant. A low $\mathrm{G}^{*}$ permits the binder to deform without producing high stresses. Binders with lower $\sin \delta$ will be more elastic, which allows the pavement structure to return to its original condition.

Results of the DSR test performed on PAV aged binders at an intermediate temperature of $25{ }^{\circ} \mathrm{C}$ are presented in Figure 3. Although it meets the Superpave specification of $5000 \mathrm{kPa}$, the $\mathrm{G}^{*} \sin \delta$ values indicate that the addition of a reclaimed binder reduced the fatigue resistance of the binder. 


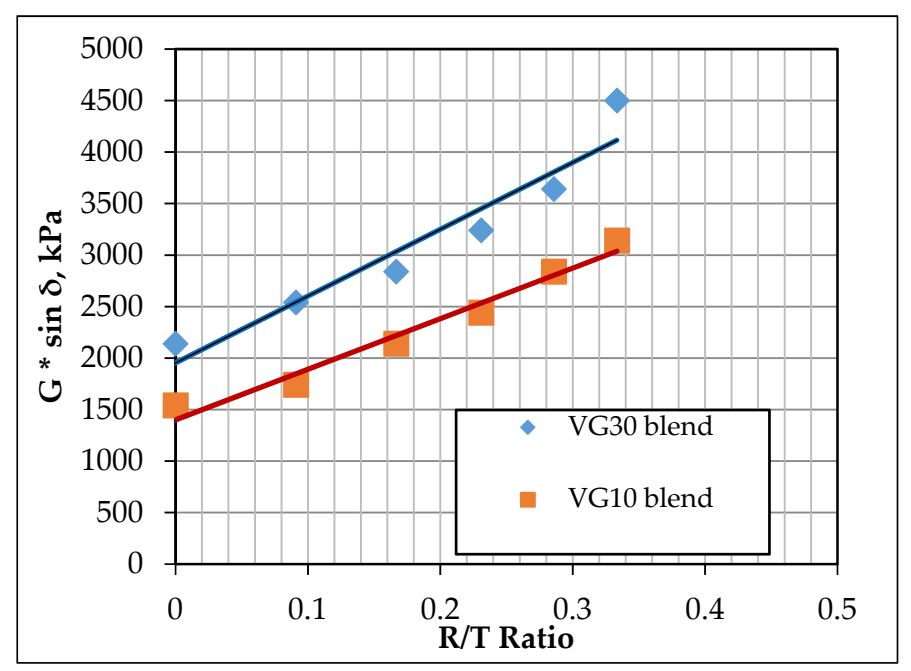

Figure 3. Variation of $\mathrm{G}^{*} \sin \delta$ with $\mathrm{R} / \mathrm{T}$ Ratio.

\subsection{Linear Amplitude Sweep Test}

Linear amplitude sweep (LAS) test was carried out on PAV-aged VG10, VG30, VG40 binders and RAP binders extracted from RAP material using a dynamic shear rheometer (DSR). The frequency sweep test was conducted at a constant amplitude of $0.1 \%$ at various frequencies varying from 0.1 to $30 \mathrm{~Hz}$. The complex modulus $\left(\mathrm{G}^{*}\right)$ and phase angle $(\delta)$ were recorded at each frequency. Strain amplitude sweep was also done at $25^{\circ} \mathrm{C}$ using oscillatory shear at a frequency of $10 \mathrm{~Hz}$. The strain was varied from $0.1 \%$ to $30 \%$. The test was conducted as per AASHTO TP 101-14 [22].

The binder fatigue life $\mathrm{N}_{\mathrm{f}}$ is estimated using Equation (3)

$$
\mathrm{N}_{\mathrm{f}}=\mathrm{A}\left(\gamma_{\max }\right)^{-\mathrm{B}}
$$

where $\gamma_{\max }$ is the maximum expected binder strain for a given pavement structure and $\mathrm{A}$ and $B$ are empirical coefficients derived from the LAS test data. A and B values obtained for virgin and recovered binders (both PAV-aged) for different RAP contents are given in Table 9. Figure 4 shows the fatigue lives estimated for the extracted binder. It is seen that fatigue life decreases with increasing RAP content. Comparing the fatigue performance of the VG40 binder with that of different blends, it appears that the VG30 blend with $0.16 \mathrm{R} / \mathrm{T}$ and VG10 blend with $0.35 \mathrm{R} / \mathrm{T}$ ratio is equivalent to VG40. 
Table 9. LAS Fatigue Model Parameters.

\begin{tabular}{ccccc}
\hline Binder & R/T Ratio & A & B & N $_{\mathbf{f}}$ (5\% Strain) \\
\hline VG10 & 0 & $12,357,742,464$ & 5.226 & $2,783,401$ \\
\hline VG10-10\% RAP & 0.09 & $9,516,625,573$ & 5.434 & $1,527,070$ \\
\hline VG10-20\% RAP & 0.16 & $8,137,621,953$ & 5.547 & $1,080,163$ \\
\hline VG10-30\% RAP & 0.23 & $7,028,025,050$ & 5.972 & 493,110 \\
\hline VG10-40\% RAP & 0.28 & $3,683,838,642$ & 6.138 & 236,365 \\
\hline VG30 & 0 & $5,492,434,229$ & 5.744 & 535,644 \\
\hline VG30-10\% RAP & 0.09 & $3,920,684,620$ & 6.000 & 207,509 \\
\hline VG30-20\% RAP & 0.16 & $2,937,455,725$ & 6.094 & 160,026 \\
\hline VG30-30\% RAP & 0.23 & $1,422,172,502$ & 6.102 & 76,295 \\
\hline VG30-40\% RAP & 0.28 & $817,174,204.6$ & 6.337 & 42,883 \\
\hline VG30-50\% RAP & 0.33 & $459,226,299$ & 6.361 & 14,932 \\
\hline VG40 & 0 & $3,683,838,642$ & 6.419 & 120,092 \\
\hline
\end{tabular}

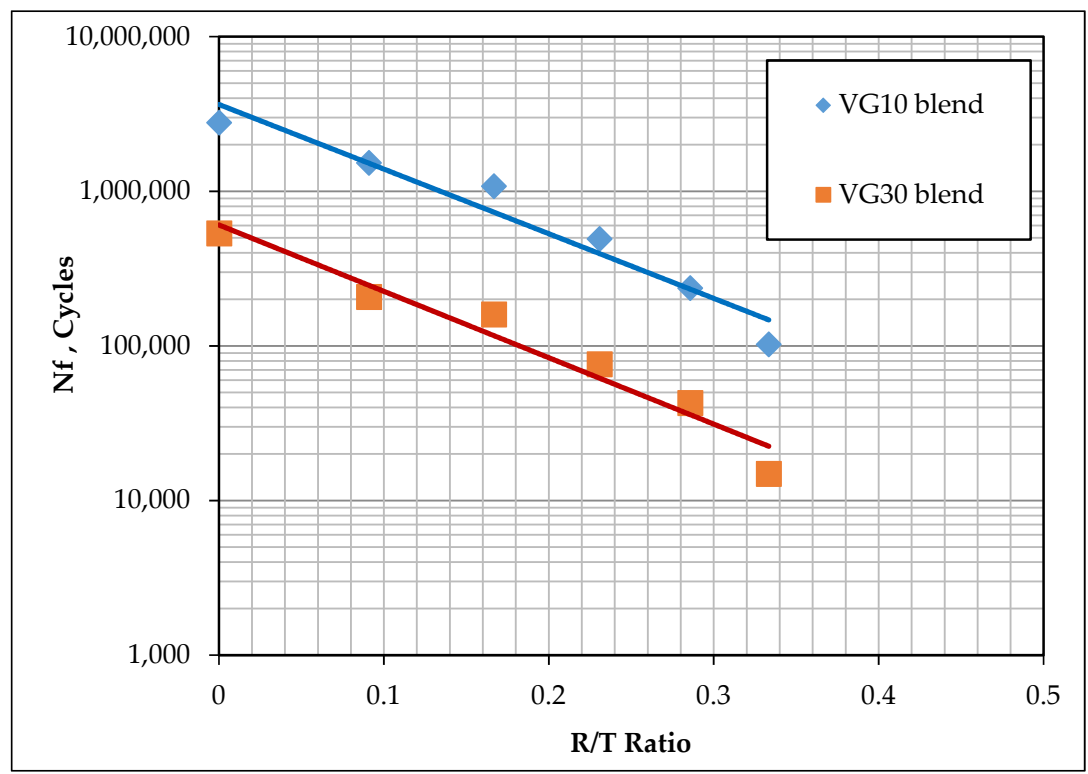

Figure 4. Binder Fatigue Lives at Different RAP\% Estimated Using LAS Test Results.

\subsection{Viscosity Blending Charts}

Figure 5 shows the viscosity-based blending chart developed as per Asphalt Institute MS-20 [23]. The virgin binder percentage (ratio of virgin binder to total binder) is determined using a log-log viscosity blending chart (Figure 5). The target viscosity for the blend of recovered bitumen and virgin bitumen is selected (VG 40). The viscosity of the extracted RAP binder on the left-hand vertical scale (A). The Virgin binder's viscosity is plotted on the right-hand scale (B). Figure 5 illustrates the virgin binder percentage (ratio of new binder to total binder) for Kharagpur RAP Source. For the VG10 new binder, the ratio of the virgin binder to the total binder is around $38 \%$, and the resulting recycled binder is $62 \%$ (100-38). Table 10 presents the proportions of recycled binder \% from the target viscosity using a blending chart for different mixes, RAP sources and virgin binders. 


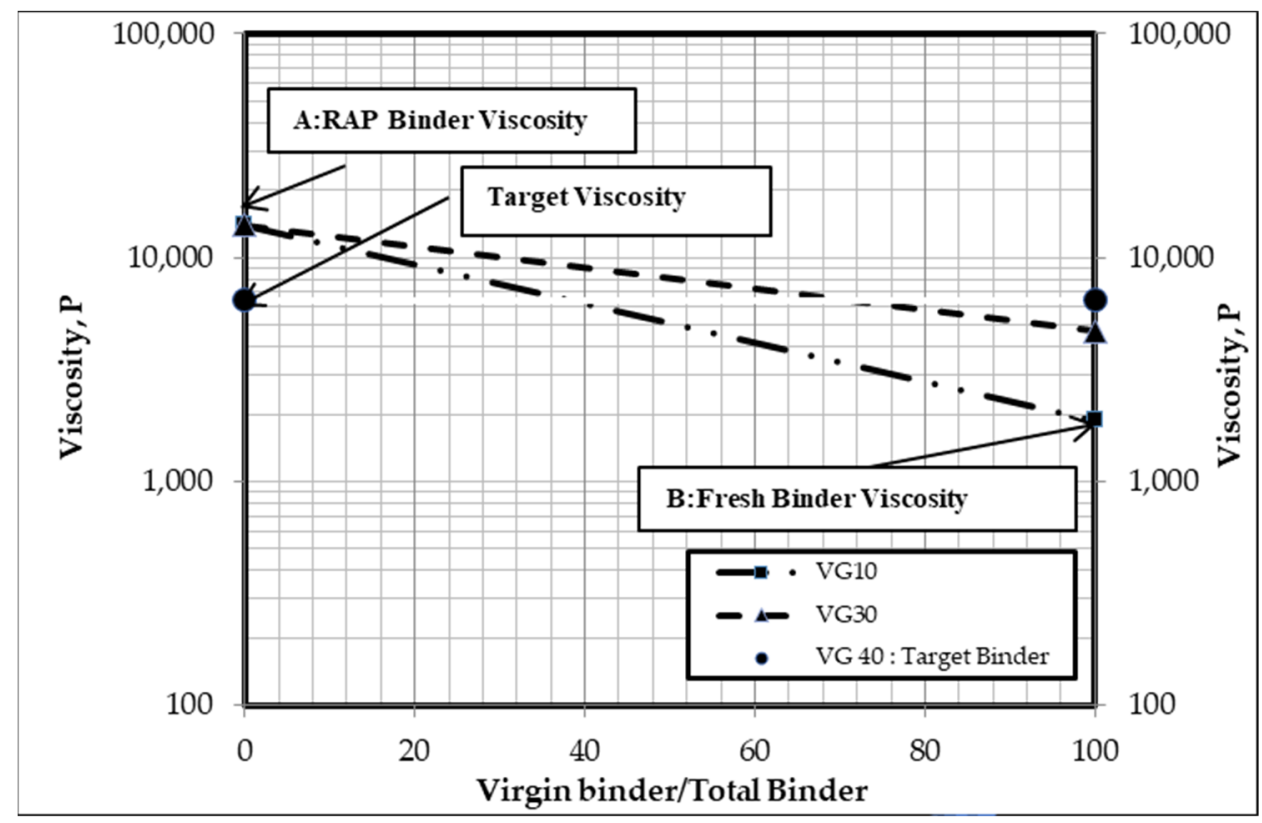

Figure 5. Viscosity Blending Chart for Kharagpur RAP.

Table 10. Recycled binder \% on Target Binder Viscosity for different RAP Sources.

\begin{tabular}{cccccccc}
\hline \multirow{2}{*}{ Mix } & \multirow{2}{*}{$\begin{array}{l}\text { Virgin } \\
\text { Binder }\end{array}$} & \multicolumn{6}{c}{ Recycled Binder \% (Recycled Binder/Total Binder) for RAP Obtained from } \\
\cline { 2 - 8 } & Kharagpur & Allahabad & Kolkata & Ongole & Varanasi & El Paso \\
\hline \multirow{2}{*}{ DBM } & VG10 & 62 & 59 & 58 & 42 & 40 & 62 \\
\cline { 2 - 8 } & VG30 & 30 & 31 & 26 & 17 & 15 & 29 \\
\hline \multirow{2}{*}{ BC } & VG10 & 72 & 68 & 67 & 49 & 47 & 72 \\
\cline { 2 - 8 } & VG30 & 35 & 36 & 30 & 19 & 18 & 34 \\
\hline \multirow{2}{*}{ SMA } & VG10 & 85 & 80 & 79 & 57 & 55 & 85 \\
\cline { 2 - 8 } & VG30 & 41 & 44 & 35 & 23 & 21 & 41 \\
\hline \multirow{2}{*}{ Texas-gap } & VG10 & 89 & 84 & 82 & 60 & 58 & 89 \\
\cline { 2 - 8 } & VG30 & 43 & 45 & 37 & 24 & 22 & 41 \\
\hline \multirow{2}{*}{ Texas-b } & VG10 & 63 & 60 & 60 & 43 & 41 & 64 \\
\cline { 2 - 8 } & VG30 & 31 & 32 & 27 & 17 & 16 & 30 \\
\hline
\end{tabular}

\section{RAP Contents from the Consideration of Equivalence with VG40 Target Binder}

By comparing the properties of RAP and virgin binder blends obtained with different proportions of RAP with the properties of VG40 target binder, the R/T ratios at which the property of blend and VG40 target binder will be similar are given in Table 11. The blend corresponding to RAP percentages (recycled binder to total binder percentage) for different types of mixes has been selected as the optimum bitumen content for each RAP content estimated from the mix design exercise presented in Bharath [14]. From Table 11, a wide range of RAP\% was observed from test parameter to parameter for all the selected gradations. Different agencies follow different test parameters for the selection of Virgin binder grade/RAP\%. Stiffer binder in RAP material typically increases mixture stiffness, which is generally believed to lead to inferior fatigue performance. In this study, the LAS test is considered for fatigue performance. Thus, a lower amount of RAP\% was obtained that meets fatigue performance criteria.

Table 11. R/T Ratios at Which Property of Blend is Similar to That of VG40.

\begin{tabular}{|c|c|c|c|c|c|c|}
\hline \multirow{2}{*}{ Parameter } & \multirow{2}{*}{$\begin{array}{c}\text { Base Binder } \\
\text { Type }\end{array}$} & \multirow{2}{*}{$\begin{array}{c}\mathrm{R} / \mathrm{T} \text { for Property } \\
\text { Equivalent to That of VG40 }\end{array}$} & \multicolumn{4}{|c|}{ Recycled Binder to Total Binder \% } \\
\hline & & & BC & DBM & SMA & Texas Gap \\
\hline Penetration & & 0.6 & 77 & 67 & 91 & 94 \\
\hline Softening Point & & 0.4 & 51 & 45 & 59 & 62 \\
\hline $\mathrm{G}^{*} / \sin \delta$ & VG10 & 0.42 & 54 & 47 & 62 & 65 \\
\hline
\end{tabular}




\section{Restriction of RAP from Aggregate Gradation Consideration}

Processing of RAP changes its aggregate gradation. The quantity of fine aggregate material generated while processing RAP material limits the maximum RAP \% added in a bituminous mixture. Separation (fractionation) of RAP material into different sizes permits the use of higher amounts of RAP material. For this study, RAP material from six different sources was collected from different places (five in India and one in the USA). In terms of gradation, three dense graded bituminous mixes and two gap graded mixes were considered. Table 12 gives the maximum RAP content permissible from target gradation consideration without fractionation. The permissible RAP \% (Percentage RAP aggregate to total aggregates) was obtained in a way such that no single sieve size will have excess material than that of the target gradation.

Table 12. Maximum Permissible RAP \% Based on Target Aggregate Gradation.

\begin{tabular}{cccccccc}
\hline \multirow{2}{*}{ Mix } & \multirow{2}{*}{$\begin{array}{c}\text { Type of } \\
\text { Gradation }\end{array}$} & \multicolumn{6}{c}{ Permissible RAP\% for RAP Source } \\
\cline { 3 - 8 } & Kharagpur & Allahabad & Kolkata & Ongole & Varanasi & El Paso \\
\hline DBM & Dense & 46 & 34 & 40 & 36 & 45 & 48 \\
\hline BC & Dense & 43 & 31 & 36 & 33 & 42 & 44 \\
\hline Texas-b & Dense & 45 & 32 & 46 & 51 & 47 & 46 \\
\hline SMA & Gap & 35 & 45 & 16 & 15 & 18 & 21 \\
\hline Texas-gap & Gap & 30 & 36 & 15 & 12 & 16 & 14 \\
\hline
\end{tabular}

\section{Conclusions}

This study evaluated the effect of RAP binder on the stiffening of the binder and rutting performance and fatigue characteristics and consequently on the maximum proportion of RAP that can be used in mixes of different gradation (dense and gap graded) mixes. The following can be concluded based on binder evaluation:

- An increase in the RAP binder content in the blend of RAP and virgin binders resulted in the stiffening of the blends in terms of reduced penetration, increase in softening point and increase in complex modulus $\left(\mathrm{G}^{*}\right)$.

- $\mathrm{G}^{*} / \sin \delta$ parameter increased and the non-recoverable creep compliance $\left(\mathrm{J}_{\mathrm{nr}}\right)$ reduced with an increase in $\mathrm{R} / \mathrm{T}$ ratio, indicating the beneficial effect of the addition of RAP in improving the rutting performance of the binder.

- The fatigue parameter $G^{*} \sin \delta$ increased with an increase in the R/T ratio. Similarly, the binder fatigue life, estimated from the LAS test, decreased with an increase in the $\mathrm{R} / \mathrm{T}$ ratio.

- The results indicate that higher RAP contents enhanced rutting resistance and reduced fatigue resistance as expected. However, it is feasible to mix RAP with softer virgin binder to obtain gap graded mixes.

- The maximum permissible proportion RAP in the mix, estimated from aggregate gradation consideration, varied significantly with RAP and target gradation source. In most of the cases, it was found that allowable RAP percentages are lower for the gap gradations compared to those of dense gradations.

From both the consideration of meeting target gradation and binder performance characteristics, higher proportions of RAP are generally permissible from binder performance consideration. The proportion of RAP in a mix can be increased by selecting an appropriate gradation for a RAP source or by using a suitable RAP source for a given gradation, although meeting the target aggregate gradation can be more restrictive.

Author Contributions: B.G.—conceptualization, methodology, writing-review and editing, formal analysis, investigation, resources, data curation; S.R.K.-supervision; V.T.-supervision; A.R.M.supervision; R.S.M.-writing-review and editing. All authors have read and agreed to the published version of the manuscript. 
Funding: Department of Civil Engineering, UTEP, El Paso, TX, USA.

Data Availability Statement: Not applicable.

Conflicts of Interest: The authors declare no conflict of interest.

\section{References}

1. Copeland, A. Reclaimed Asphalt Pavement in Asphalt Mixtures: State of the Practice; Report Number FHWA-HRT-11- 021; TurnerFairbank Highway Research Center: McLean, VA, USA, 2011.

2. Lee, J.; Denneman, E.; Choi, Y. Maximising the Re-Use of Reclaimed Asphalt Pavement Outcomes of Year Two: RAP Mix Design, AP-T286-15; Austroads: Sydney, Australia, 2015.

3. White, G.; Jamshidi, A. Extending the use of RAP in airport asphalt resurfacing. In Proceedings of the RILEM International Symposium on Bituminous Materials, Lyon, France, 14-16 December 2020.

4. Indian Roads Congress (IRC). IRC: 120: Recommended Practice for Recycling of Bituminous Pavements; IRC: New Delhi, India, 2015.

5. The Asphalt Institute. MS-2: Asphalt Mix Design Methods, 7th ed.; Manual Series No. 2; The Asphalt Institute: Lexington, KY, USA, 2015.

6. Ministry of Road Transport and Highways (MoRTH). Specifications for Road and Bridge Works, 5th Revision; Indian Roads Congress: New Delhi, India, 2013.

7. European Committee for Standardization. EN 13108-1: Bituminous Mixtures: Material Specifications: Part 1: Asphalt Concrete; European Committee for Standardization: Bruxelles, Belgium, 2006.

8. European Committee for Standardization. EN 13108-8: Bituminous Mixtures: Material Specifications: Part 8: Reclaimed Asphalt; European Committee for Standardization: Bruxelles, Belgium, 2005.

9. McDaniel, R.S.; Soleymani, H.; Anderson, R.M.; Turner, P.; Peterson, R. Recommended Use of Reclaimed Asphalt Pavement in the Superpave Mix Design Method. NCHRP Web Document, 30. 2000. Available online: http:/ / onlinepubs.trb.org/onlinepubs/ nchrp/nchrp_w30-a.pdf (accessed on 4 August 2021).

10. Indian Roads Congress (IRC). IRC: 37: Tentative Guidelines for Design of Flexible Pavements; IRC: New Delhi, India, 2018.

11. American Society for Testing and Materials (ASTM). ASTM D3381-18: Standard Specification for Viscosity-Graded Asphalt Binder for Use in Pavement Construction; ASTM: West Conshohocken, PA, USA, 2018.

12. Indian Roads Congress (IRC). IRC: 111: Specifications for Dense Graded Mixes; IRC: New Delhi, India, 2018.

13. Texas Department of Transportation (TxDOT). Standard Specifications for Construction and Maintenance of Highways, Streets and Bridges; TxDOT: Austin, TX, USA, 2004.

14. Bharath, G. Performance Characteristics of Bituminous Mixtures Containing Recycled Asphalt Pavement Material. Ph.D. Thesis, Civil Engineering Department, Indian Institute of Technology, Kharagpur, India, 2016.

15. American Society for Testing and Materials (ASTM). ASTM D36-14: Standard Test Method for Softening Point of Bitumen (Ring-andBall Apparatus); ASTM: West Conshohocken, PA, USA, 2014.

16. American Society for Testing and Materials (ASTM). ASTM D5/D5M-20: Standard Test Method for Penetration of Bituminous Materials; ASTM: West Conshohocken, PA, USA.

17. Bureau of Indian Standards (IS). IS: 73: Paving Bitumen-Specification, 4th Revision; IS: New Delhi, India, 2013.

18. Asphalt Institute. SP-1: Superpave Performance Graded Asphalt Binder Specification and Testing, Asphalt Institute, 3rd ed.; Superpave Series No. 1; Asphalt Institute: Lexington, KY, USA, 2003.

19. American Society for Testing and Materials (ASTM). ASTM D7175-15: Standard Test Method for Determining the Rheological Properties of Asphalt Binder Using a Dynamic Shear Rheometer; ASTM: West Conshohocken, PA, USA, 2015.

20. American Society for Testing and Materials (ASTM). ASTM D7405-10: Standard Test Method for Multiple Stress Creep and Recovery Test (MSCR) of Asphalt Binder using a Dynamic Shear Rheometer; ASTM: West Conshohocken, PA, USA, 2010.

21. Roberts, F.L.; Kandhal, P.S.; Lee, D.Y.; Kennedy, T.W. Hot Mix Asphalt Materials, Mixture Design and Construction, 2nd ed.; Lanham, M.D., Ed.; NAPA Research and Education Foundation: Forbes Boulevard, Lanham, USA, 1996.

22. American Association of State Highway and Transportation Officials (AASHTO). AASHTO TP 101-14: Estimating Damage Tolerance of Asphalt Binders Using the Linear Amplitude Sweep; AASHTO: Washington, DC, USA, 2014.

23. The Asphalt Institute. MS-20: Asphalt Hot Mix Recycling, 2nd ed.; Manual Series No -20; The Asphalt Institute: Lexington, KY, USA, 1986. 